\title{
INFLUENCE OF VARIATION OF ETCHING CONDITIONS ON THE SENSITIVITY OF PADC DETECTORS WITH A NEW EVALUATION METHOD
}

\author{
A. Fiechtner-Scharrer ${ }^{1}$, S. Mayer ${ }^{1, *}$, M. Boschung ${ }^{1}$ and A. Whitelaw ${ }^{2}$ \\ ${ }^{1}$ Paul Scherrer Institut, 5232 Villigen PSI, Switzerland \\ ${ }^{2}$ University of St. Andrews, St. Andrews KY16 9SS, UK \\ *Corresponding author: sabine.mayer@psi.ch
}

\begin{abstract}
At the Paul Scherrer Institut, a personal neutron dosimetry system based on chemically etched poly allyl diglycol carbonate (PADC) detectors and an automatic track counting (Autoscan 60) for neutron dose evaluations has been in routine use since 1998. Today, the hardware and the software of the Autoscan 60 are out of date, no spare components are available anymore and more sophisticated image-analysis systems are already developed. Therefore, a new evaluation system, the 'TASLIMAGE', was tested thoroughly in $\mathbf{2 0 0 9}$ for linearity, reproducibility, influence of etching conditions and so forth, with the intention of replacing the Autoscan 60 in routine evaluations. The TASLIMAGE system is based on a microscope (high-quality Nikon optics) and an ultra-fast three-axis motorised control for scanning the detectors. In this paper, the TASLIMAGE system and its possibilities for neutron dose calculation are explained in more detail and the study of the influence of the variation of etching conditions on the sensitivity and background of the PADC detectors is described. The etching temperature and etching duration were varied, which showed that the etching conditions do not have a significant influence on the results of non-irradiated detectors. However, the sensitivity of irradiated detectors decreases by $5 \%$ per $1^{\circ} \mathrm{C}$ when increasing the etching temperature. For the variation of the etching duration, the influence on the sensitivity of irradiated detectors is less pronounced.
\end{abstract}

\section{INTRODUCTION}

At the Paul Scherrer Institut (PSI), a personal neutron dosimetry system ${ }^{(1)}$ based on chemically etched poly allyl diglycol carbonate (PADC) detectors and an automatic track counting (Autoscan 60) for neutron dose evaluations has been in routine use since 1998. In 2009, a new evaluation system, the 'TASLIMAGE', was tested thoroughly for linearity, reproducibility, influence of etching conditions and so forth, with the intention of replacing the Autoscan 60 in routine evaluations. In this paper, the first studies of the influence of the variation of etching conditions on the sensitivity and background of the PADC detectors and the various neutron dose evaluation possibilities of TASLIMAGE are described.

\section{MATERIALS AND METHODS}

\section{Dosemeter and reference field}

In this study, neutron detection is performed using TASTRAK ${ }^{\text {TM }}$ track etch detectors purchased from Track Analysis Systems Ltd (TASL). For irradiations, the detectors were placed in the routine dosemeter holder of PSI for measuring neutrons with energies above $200 \mathrm{keV}$ (Figure 1). The dosemeters were irradiated on an ISO water slab phantom $\left(30 \times 30 \times 15 \mathrm{~cm}^{3}\right)$. All irradiation tests were performed with a ${ }^{241} \mathrm{Am}-\mathrm{Be}$ neutron source at the calibration laboratory of PSI.

\section{Etching procedure}

PADC detectors are etched chemically to evaluate the neutron dose. The standard etching procedure recommended by the manufacturer is etching for $2 \mathrm{~h}$ and 50 min with $6.25 \mathrm{~N} \mathrm{NaOH}$ at $85^{\circ} \mathrm{C}$.

Other etching parameters could be chosen either by accident (human or technical error) or with the intention to improve the etching/evaluation procedure. In order to determine the effects on the sensitivity of the PADC detectors, the influence of the variation of the temperature and the duration of the etching was investigated. First, the temperature was varied from $76^{\circ} \mathrm{C}$ up to $92^{\circ} \mathrm{C}$ by applying a constant etching duration of $2 \mathrm{~h}$ and $50 \mathrm{~min}$. Second, the etching duration was varied from $2 \mathrm{~h} 30 \mathrm{~min}$ up to $3 \mathrm{~h} 10 \mathrm{~min}$ at a constant temperature of $85^{\circ} \mathrm{C}$.

After the etching, the detectors were neutralised for $15 \mathrm{~min}$ in $0.1 \mathrm{M} \mathrm{HCl}$ at room temperature and then washed for $10 \mathrm{~min}$ in distilled water at $60^{\circ} \mathrm{C}$ and for $10 \mathrm{~min}$ in distilled water at room temperature. No prior etching with a mixture of methanol and $\mathrm{NaOH}$ to polish the detector surface ('preetching') was done.

\section{The evaluation system TASLIMAGE}

After etching, the detectors were evaluated with the TASLIMAGE evaluation system ${ }^{(2)}$ (software version V11.3.2.133), as shown in Figure 2. The system is based on a conventional transmission light microscope (high-quality Nikon optics) and an ultra-fast 


\section{INFLUENCE OF VARIATION OF ETCHING CONDITIONS}

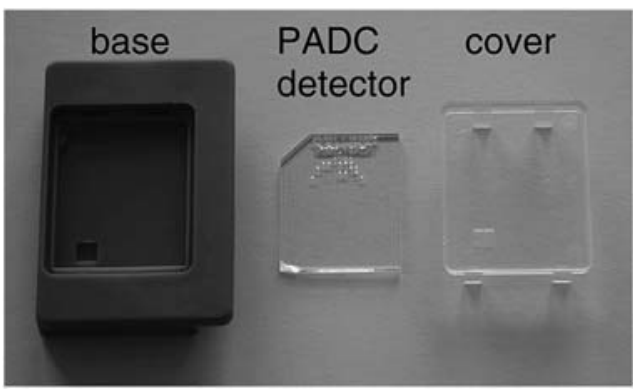

Figure 1. Neutron dosemeter.

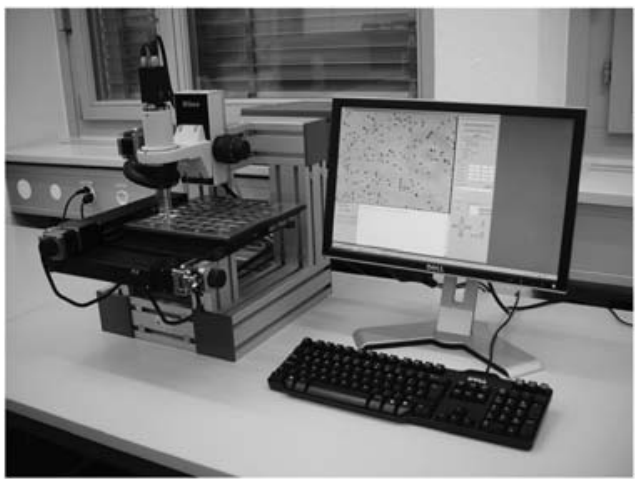

Figure 2. The evaluation system TASLIMAGE. Left: Scanning system and microscope. Right: Software and control system.

three-axis motorised control. It acquires the images of the etched tracks at a high magnification. The evaluation procedure has an autofocus that locks on the detector surface. The autofocus ensures a good focus throughout the scan and compensates for nonflat detectors and movements during the scan. For each scan, a noise filter is applied to remove localised noise, such as patches of dust or dirt on the surface of the detector. Each measured track is characterised by many parameters, such as size, shape, diameter, image symmetry, optical density, track length, quality of measurement and so forth. In the neutron dose calculation, 20 of these parameters are used actively to enable good noise discrimination, sensitivity calibration and dose calculation. Since the system can discriminate between etched tracks and background objects, the former recommended procedure (pre-etching) of polishing the surface of the detector with methanol is not necessary ${ }^{(2)}$. The neutron sensitivity of PADC detectors can vary between different production batches of material. TASLIMAGE is able to perform a sensitivity calibration and individual neutron dose calculation by comparing the individual track characteristics with an extensive database where scans of different material sensitivities, irradiations with different neutron doses and neutron energies are stored. In our system, such a database exists for three different etching procedures:

- Database 'standard':

Etching: $2 \mathrm{~h}$ and $50 \mathrm{~min}$ at $85^{\circ} \mathrm{C}$ in $6.25 \mathrm{~N}$ $\mathrm{NaOH}$

- Database 'A':

Pre-etching: $1 \mathrm{~h}$ in $60 \%$ methanol and $40 \%$ $6.25 \mathrm{~N} \mathrm{NaOH}$ at $70^{\circ} \mathrm{C}$

Etching: $6 \mathrm{~h}$ at $75^{\circ} \mathrm{C}$ in $6.25 \mathrm{~N} \mathrm{NaOH}$

- Database 'B':

Pre-etching: $1 \mathrm{~h}$ in $60 \%$ methanol and $40 \%$ $6.25 \mathrm{~N} \mathrm{NaOH}$ at $70^{\circ} \mathrm{C}$

Etching: $6 \mathrm{~h}$ at $70^{\circ} \mathrm{C}$ in $6.25 \mathrm{~N} \mathrm{NaOH}$

The neutron dose calculation is always performed for a group of scans of associated detectors. Associated detectors mean that the detectors belong to the same production batch and are handled and etched the same way. This concerns the storage conditions, the conditions of use and the dosemeter holder used. Depending on the applied etching procedure, an appropriate database ('standard', 'A' or ' $\mathrm{B}$ ') is chosen in the evaluation software. Then there are two options for the neutron dose calculation. Using option 1, the neutron dose is calculated based on ALL scans of the group of associated detectors. It is recommended that there are scans of at least eight detectors with a dose of $\sim 5 \mathrm{mSv}$ in the group. With each new scan, the group of associated detectors is expanded and the resulting neutron doses are recalculated and may differ slightly. To avoid the latter effect, the alternative option 2 can be chosen, where a group of detector scans can be selected manually and denoted as ' $\mathrm{X}$ calibration set'. The neutron doses of all detectors are then calculated based only on these calibration scans. Advisably a set of at least eight detectors with a neutron dose of at least $\sim 5 \mathrm{mSv}$, as already mentioned above, should be used.

\section{MEASUREMENTS}

The following etching conditions were investigated:

- Etching temperature of 76, 79, 82, 85, 88 and $92^{\circ} \mathrm{C}$ at a constant etching duration of $2 \mathrm{~h}$ and $50 \mathrm{~min}$.

- Etching duration of 2 h $30 \mathrm{~min}, 2 \mathrm{~h} 40 \mathrm{~min}, 2 \mathrm{~h}$ $50 \mathrm{~min}, 3$ and $3 \mathrm{~h} 10 \mathrm{~min}$, at a constant etching temperature of $85^{\circ} \mathrm{C}$.

For each etching condition, a group of 8 unirradiated detectors and 10 irradiated detectors were used. The latter detectors were irradiated with a personal neutron dose equivalent, $H_{\mathrm{p}}(10)$, of $3 \mathrm{mSv}$. To investigate the difference of the available database 


\section{A. FIECHTNER-SCHARRER ET AL.}

options in the evaluation system, for each etching condition, the neutron doses were calculated separately, applying always successively the three different databases 'standard', 'A' and 'B' (neutron dose calculation using option 1). Beside these evaluations, the neutron doses were also calculated using option 2 , where an additional calibration set of 10 detectors was defined for each etching condition. For this purpose, a second group of detectors was irradiated with a neutron dose equivalent $H_{\mathrm{p}}(10)$ of $6 \mathrm{mSv}$, and this group was used as an $\mathrm{X}$ calibration set and was etched with the standard etching procedure (etching for $2 \mathrm{~h} 50 \mathrm{~min}$ at $85^{\circ} \mathrm{C}$ ). For the neutron dose calculation with the $\mathrm{X}$ calibration set, only the 'standard' database was applied.

\section{RESULTS}

\section{Influence on unirradiated detectors}

In Table 1, the results of unirradiated detectors for all etching conditions and chosen databases are shown. The variation of etching duration and etching temperature does not have a significant influence on the measured doses of unirradiated detectors. Measured doses vary from -0.01 up to 0.09

Table 1. Measured doses in $\mathrm{mSv}$ of not irradiated detectors for various etching conditions. Note that dose values can be negative because an algorithm is applied that may substract a non-representative background. Uncertainties are single standard deviations.

Etching condition

Measured doses in mSv of not irradiated detectors

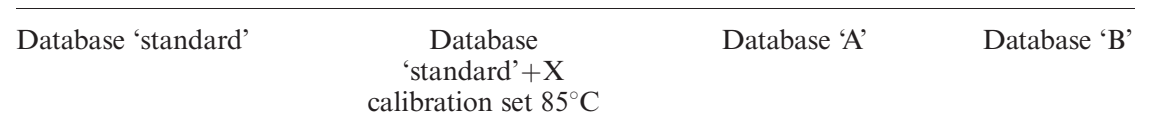

\begin{tabular}{|c|c|c|c|c|}
\hline $2 \mathrm{~h} 50 \mathrm{~min}, 76^{\circ} \mathrm{C}$ & $0.11 \pm 0.17$ & $0.00 \pm 0.05$ & $0.11 \pm 0.17$ & $0.09 \pm 0.15$ \\
\hline $2 \mathrm{~h} 50 \mathrm{~min}, 79^{\circ} \mathrm{C}$ & $0.00 \pm 0.03$ & $0.01 \pm 0.04$ & $0.00 \pm 0.03$ & $0.00 \pm 0.02$ \\
\hline $2 \mathrm{~h} 50 \mathrm{~min}, 82^{\circ} \mathrm{C}$ & $-0.01 \pm 0.03$ & $-0.01 \pm 0.05$ & $-0.01 \pm 0.04$ & $0.00 \pm 0.04$ \\
\hline $2 \mathrm{~h} 50 \mathrm{~min}, 85^{\circ} \mathrm{C}$ & $0.00 \pm 0.01$ & $0.00 \pm 0.02$ & $0.00 \pm 0.01$ & $-0.01 \pm 0.01$ \\
\hline $2 \mathrm{~h} 50 \mathrm{~min}, 88^{\circ} \mathrm{C}$ & $0.00 \pm 0.02$ & $0.03 \pm 0.06$ & $0.00 \pm 0.03$ & $0.00 \pm 0.02$ \\
\hline $2 \mathrm{~h} 50 \mathrm{~min}, 92^{\circ} \mathrm{C}$ & $0.00 \pm 0.01$ & $-0.01 \pm 0.01$ & $0.00 \pm 0.01$ & $0.00 \pm 0.01$ \\
\hline $2 \mathrm{~h} 30 \mathrm{~min}, 85^{\circ} \mathrm{C}$ & $0.00 \pm 0.02$ & $0.01 \pm 0.03$ & $0.00 \pm 0.02$ & $0.01 \pm 0.02$ \\
\hline $2 \mathrm{~h} 40 \mathrm{~min}, 85^{\circ} \mathrm{C}$ & $0.00 \pm 0.02$ & $0.00 \pm 0.04$ & $0.00 \pm 0.02$ & $0.00 \pm 0.02$ \\
\hline $2 \mathrm{~h} 50 \mathrm{~min}, 85^{\circ} \mathrm{C}$ & $0.00 \pm 0.01$ & $0.00 \pm 0.02$ & $0.00 \pm 0.01$ & $-0.01 \pm 0.01$ \\
\hline $3 \mathrm{~h} 00 \mathrm{~min}, 85^{\circ} \mathrm{C}$ & $0.02 \pm 0.05$ & $0.06 \pm 0.12$ & $0.02 \pm 0.05$ & $0.02 \pm 0.04$ \\
\hline $3 \mathrm{~h} 10 \mathrm{~min}, 85^{\circ} \mathrm{C}$ & $-0.01 \pm 0.01$ & $0.00 \pm 0.02$ & $-0.01 \pm 0.01$ & $0.03 \pm 0.03$ \\
\hline
\end{tabular}

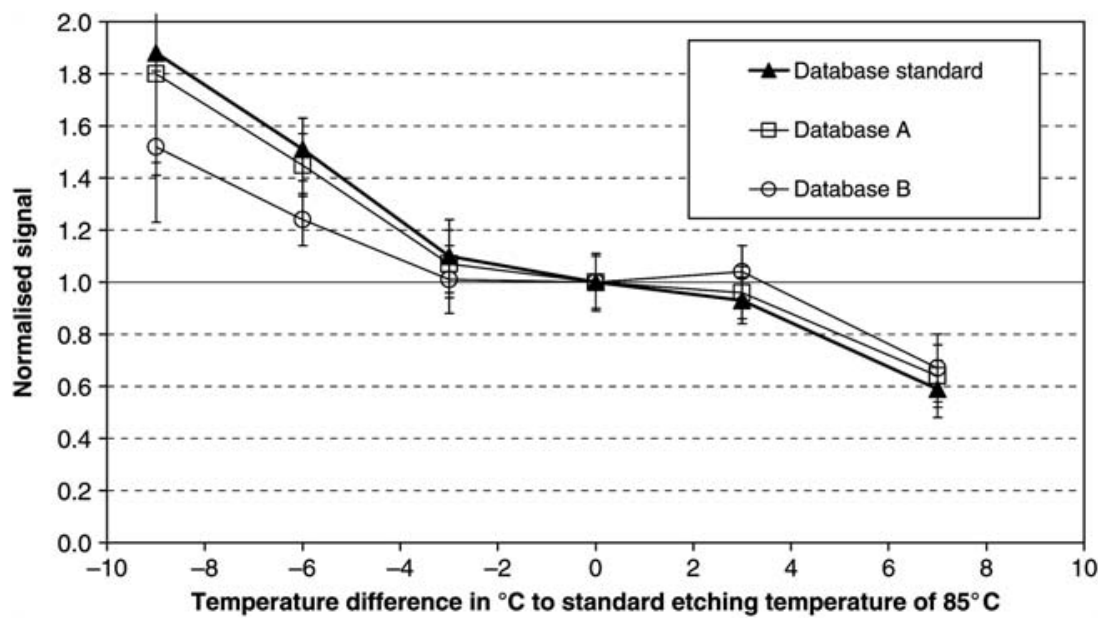

Figure 3. The signal that is normalised to the signal at the standard etching procedure in function of the variation of the etching temperature at a constant etching duration of $2 \mathrm{~h} 50 \mathrm{~min}$. Various dose calculation options of the evaluation system TASLIMAGE are shown. Uncertainties are single standard deviations. 
INFLUENCE OF VARIATION OF ETCHING CONDITIONS

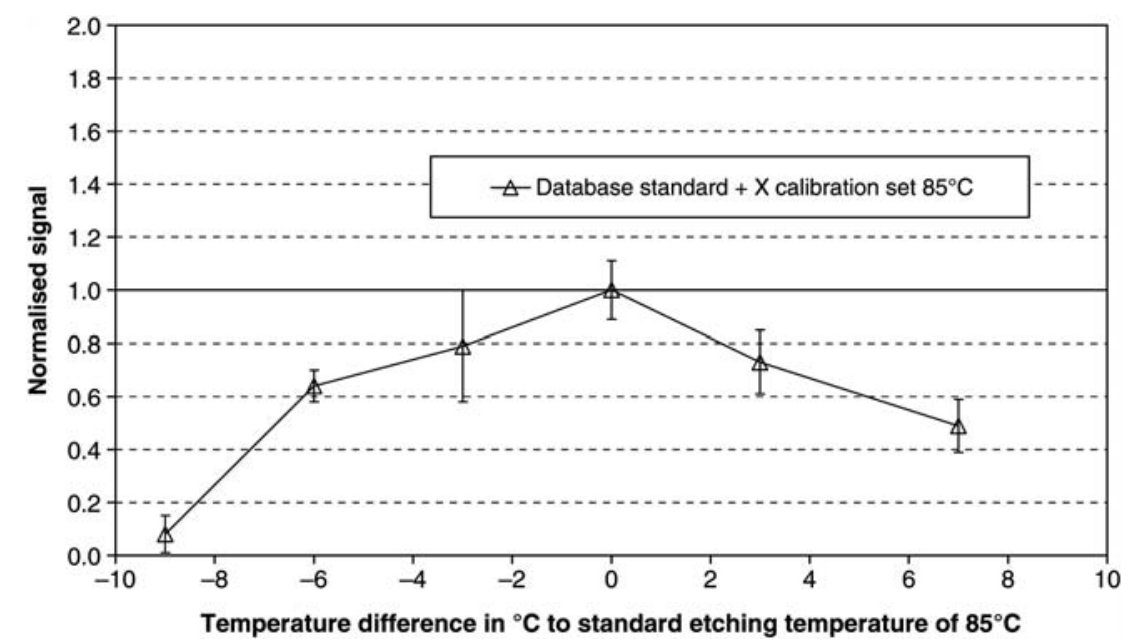

Figure 4. The signal that is normalised to the signal at the standard etching procedure in function of the variation of the etching temperature at a constant etching duration of $2 \mathrm{~h} 50 \mathrm{~min}$, applying the database 'standard' and an X calibration set. The $\mathrm{X}$ calibration set was etched for $2 \mathrm{~h} 50 \mathrm{~min}$ at $85^{\circ} \mathrm{C}$. Uncertainties are single standard deviations.

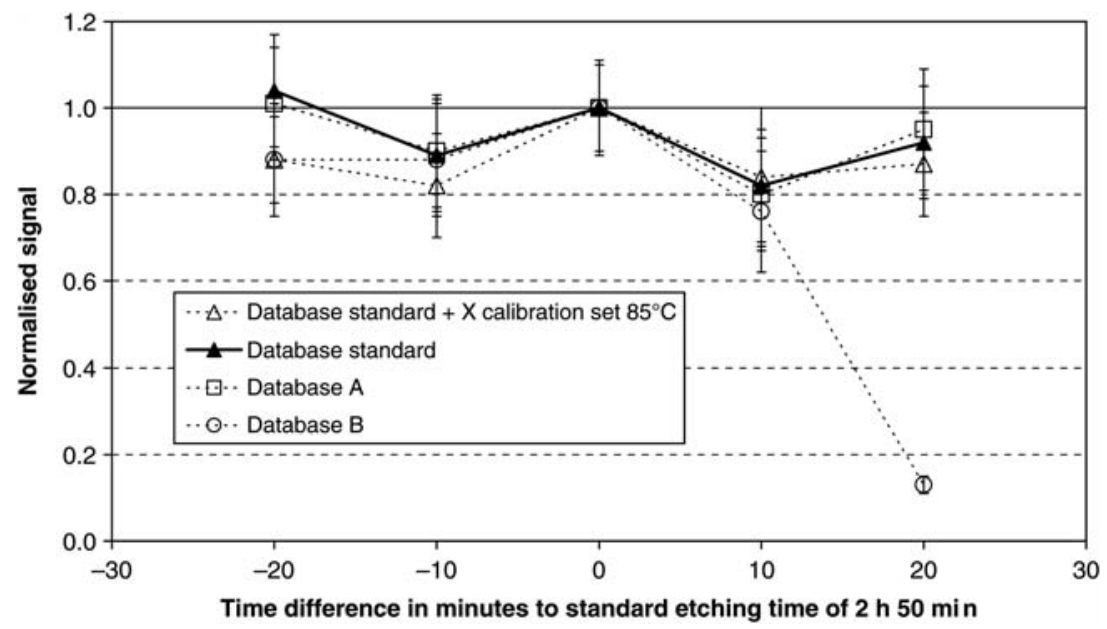

Figure 5. The signal that is normalised to the signal at the standard etching procedure in function of the variation of the etching duration at a constant etching temperature of $85^{\circ} \mathrm{C}$. Various dose calculation options of the evaluation system TASLIMAGE are shown. The low dose value for 20-min time difference (database B) could not be explained. Uncertainties are single standard deviations.

$\mathrm{mSv}$, independent of the etching conditions and database. Note that implied dose values can be negative because an algorithm that may substract a non-representative individual background is applied.

\section{Influence of etching temperature on irradiated detectors}

In Figure 3, the influence of the etching temperature on the neutron dose calculation of irradiated detectors is shown. The signal is normalised to the signal at the standard etching procedure. All uncertainties shown in Figures 3-5 are single standard deviations. If the actual etching temperature differs from the recommended standard etching temperature of $85^{\circ} \mathrm{C}$, the question which database should be applied for the neutron dose calculation comes up. For example, the database ' $\mathrm{A}$ ' might be more appropriate if the actual etching temperature is $76^{\circ} \mathrm{C}$ instead of $85^{\circ} \mathrm{C}$ (even if, strictly speaking, for using database ' $\mathrm{A}$ ' an additional pre-etching and an etching duration of $6 \mathrm{~h}$ at $75^{\circ} \mathrm{C}$ is supposed to be applied). But 


\section{A. FIECHTNER-SCHARRER ET AL.}

it turned out that for all databases, a similar tendency could be observed: the calculated neutron dose decreases with an average value of $\sim 5 \%$ per $1^{\circ} \mathrm{C}$ when increasing the etching temperature. Note that in the temperature range of $\pm 3^{\circ} \mathrm{C}\left(82-88^{\circ} \mathrm{C}\right)$, the change in the calculated neutron dose is smaller. When applying the database 'standard' and an X calibration set (Figure 4), a different tendency arises: for each etching temperature different from the standard etching temperature of $85^{\circ} \mathrm{C}$, the calculated neutron dose is up to $20-90 \%$ too low. This shows that if the actual etching temperature is, by accident or deliberately, different from $85^{\circ} \mathrm{C}$, it is not crucial which database is chosen, but an $\mathrm{X}$ calibration set should be applied in any case.

\section{Influence of etching duration on irradiated detectors}

The influence of the etching duration on irradiated detectors seems to be less pronounced (Figure 5). The signal is normalised to the signal at the standard etching procedure. For all applied databases, the deviations of the calculated doses with etching durations other than standard etching duration are between 0 and $-20 \%$, except for the calculation with database ' $\mathrm{B}$ ', where a significant decrease of $90 \%$ can be observed for the etching duration of $3 \mathrm{~h}$ $10 \mathrm{~min}$. The reason for this low value could not be explained.

\section{CONCLUSIONS}

The influence of various etching conditions on unirradiated detectors is not significant. The influence of the etching duration on the sensitivity of irradiated detectors is also not significant; the variation of calculated neutron doses is within $20 \%$. However, the influence of the etching temperature on the sensitivity of irradiated detectors is not negligible: a decrease of $\sim 5 \%$ per $1^{\circ} \mathrm{C}$ increasing temperature could be observed. Here more detailed studies on temperature steps of $1{ }^{\circ} \mathrm{C}$ are recommended. If the applied etching temperature differs from the recommended etching temperature of $85^{\circ} \mathrm{C}$, it is necessary to clarify which database should be chosen and especially, whether the application of a special calibration set is still sensible. In routine use, additional unirradiated and irradiated (at known doses) detectors would be etched in each bath to control the procedure. The results of this study indicate that the recommended etching procedure of $2 \mathrm{~h} 50 \mathrm{~min}$ at $85^{\circ} \mathrm{C}$ is applicable for routine applications.

\section{FUNDING}

This work was partly supported by the Swiss Federal Nuclear Safety Inspectorate (ENSI, contract $\mathrm{N}^{\circ}$ 100694).

\section{REFERENCES}

1. Fiechtner, A. and Wernli, C. Individual neutron monitoring with CR-39 at an accelerator centre. Radiat. Prot. Dosim. 85(1-4), 35-38 (1999).

2. Moss, G. R., Hansen, M. F., Fews, A. P. and Henshaw, D. L. TASLIMAGE-A high sensitivity neutron and radon dosimetry system. Radiat. Prot. Dosim. (this issue). 